Año L. urtea

$126-2018$

Uztaila-abendua Julio-diciembre

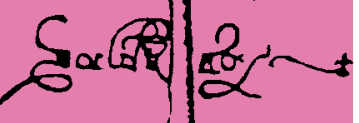
tats

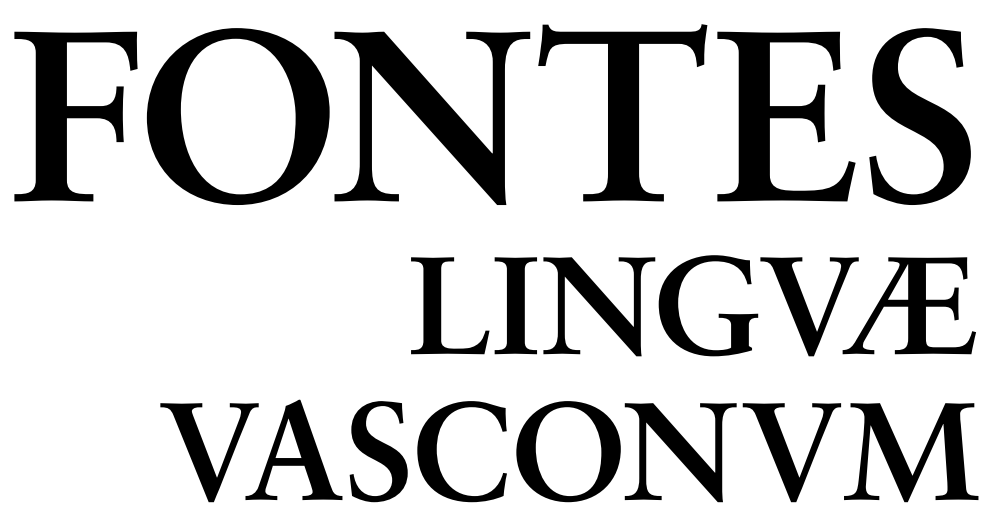

STVDIA ET DOCVMENTA

SEPARATA

\title{
Menpeko perpausetako hitz azentugabeen foku azentuaz
}

Arantzazu Elordieta, Gorka Elordieta, José Ignacio Hualde

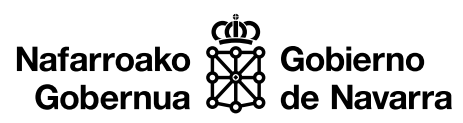

- 00 


\title{
Menpeko perpausetako hitz azentugabeen foku azentuaz
}

Sobre el acento nuclear de las palabras léxicamente átonas de las oraciones subordinadas

On focal accent of unaccented words in subordinate clauses

\author{
Arantzazu ElORDIETA \\ Euskal Herriko Unibertsitatea UPV/EHU \\ arantzazu.elordieta@ehu.eus \\ Gorka ELORDIETA \\ Euskal Herriko Unibertsitatea UPV/EHU \\ gorka.elordieta@ehu.eus \\ José Ignacio HUALDE \\ University of Illinois at Urbana-Champaign \\ jihualde@illinois.edu
}

\begin{abstract}
Eskerrik beroenak eman nahi dizkiegu gure hiztunei, beraien denbora eta hain datu baliagarriak eskaintzeagatik. Lan honen bi zuzentzaile anonimoei ere eskerrak eman nahi dizkiegu, egin dizkiguten oharrei esker lanak sendotasuna eta argitasuna irabazi duela uste baitugu. Jon Ortiz de Urbinari ere gure eskerrona adierazi nahi diogu, bere lan aitzindariek eta bere analisi fin eta dotoreetarako maisutasunak inspiratu baitituzte hemen aurkezten dugun bezalako ikerlanak. Azkenik, ikerketa hau Eusko Jaurlaritzako dirulaguntza jasotzen duen Hizkuntzalaritza Teorikorako Taldea (HiTT) GIC12/61 IT769-13 eta Euskal Herriko Unibertsitateko FIU 11/14 ikerketa taldeen ekintzen barruan kokatzen da.
\end{abstract}

Jasotze data: 2018/03/12. Behin-behineko onartze data: 2018/09/04. Behin betiko onartze data: 2018/09/19. 


\section{LABURPENA}

Lan honetan Lekeitioko hizkeran menpeko perpausetako azentu nagusia non kokatzen den aztertzen dugu, asimetria interesgarri bat erakutsiz. -ela perpaus barruan dagoen aditzaren aurreko hitz azentugabeak foku azentua jaso dezakeen bitartean, -en, -enean, -enétik, -elako perpaus barrukoak ezin du azentua eraman. Enpirikoki baieztatu dugu kontrastea gertatu egiten dela, eta kontrastea azaltzeko proposatzen dugu auzia ez datzala osagarri-adjunktu bereizketan, baizik eta zein fase-eremu sintaktikori eragiten dion azentu ezarketak menpeko perpausetan. Horretarako, iradokitzen dugu -ela izan ezik, beste konplementatzaileak posposiziodunak direla eta, ondorioz, fase desberdinetan ezartzen dela azentua.

Gako hitzak: azentu nagusia; fasea; menpeko perpausa; posposizioa.

\section{RESUMEN}

Examinamos la posición del acento nuclear en varias oraciones subordinadas de la variedad del vasco de Lekeitio y describimos una nueva asimetría. Mientras que una palabra léxicamente átona que precede al verbo subordinado lleva el acento nuclear en oraciones con -ela 'que', no es así en otros tipos de subordinadas. Verificamos este contraste empíricamente y ofrecemos un análisis sintáctico para la asimetría. Nuestra propuesta es que la explicación tiene que ver con el dominio de fase sintáctica en el que se asigna el acento. Sugerimos que, con la excepción de -ela, todos los otros subordinantes son complementantes pospositivos y que, en consecuencia, el acento se asigna en fases diferentes.

Palabras clave: acento nuclear; fase; cláusulas subordinadas; posposición.

\section{ABSTRACT}

We examine the position of the sentential main accent in subordinate clauses in Lekeitio Basque describing a new asymmetry. Whereas a lexically unaccented word preceding the subordinate verb in a clause with -ela 'that' will carry the main accent, that is not true in clauses with other complementizers. We empirically verify this unusual contrast and provide a syntactic analysis for this asymmetry. We propose that the explanation has to do with the phase-domain where accent assignment takes place. We suggest that, except for -ela, all other complementizers are postpositional and that, consequently, accent is assigned at different phases.

Keywords: Nuclear stress; phase; embedded sentence; postposition. 
1. Sarrera. 2. Metodologia. 3. Emaitzak. 4. Analisi sintaktikoa. 4.1. Kontrastea: -ela vs. beste konplementatzaileak. 4.2. Azentua eta faseak. 5. ONDORIOAK. 6. ERREFERENTZIAK. 7. ERANSKINA.

\section{SARRERA}

Lekeition eta oro har Bizkaiko iparraldeko hizkeretan hitzak bi taldetan banatzen dira prosodiaren aldetik: badira hitz azentudunak eta azentugabeak (Hualde, 1997; Hualde, Elordieta \& Elordieta, 1994, besteak beste). Azentudunek azentua beti silaba jakin batean daramate, gaztelaniaren edo ingelesaren hitz lexikalek bezala. Azentugabeek, aldiz, ez dute berez azenturik.

Horrez gain, badago hala ere murriztapen bat esaldiaren prosodian: azentu bat gauzatu behar da edo aditzaren aurrean dagoen sintagman edo aditzean bertan. Ez dago, beraz, azenturik gabeko esaldirik. (1) adibidean hitz guztiak azentudunak dira. (2)-n, berriz, denak azentugabeak dira, baina badago azentu bat aditzaren aurrean. Jun-ek eta G. Elordietak (1997) azentu honi 'derived accent' edo azentu deribatua deitzen diote (ikus aurretik Hualde, Elordieta \& Elordieta, 1993). Hurrengo esaldiak lekeitierazkoak dira:

1 Aditz nagusiak eta laguntzaileak unitate bat (hitz prosodiko bat) osatzen dute azentu ezarketarako, horregatik idatzi dugu aditzen sekuentzia gidoi batekin. (1)-eko esaldian, bi aditzek osatzen duten unitatearen azkenaurreko silaban ezartzen da azentua, ez aditz nagusiaren azkenaurreko silaban. (2)-ko esaldian ez da azenturik nabaritzen bi aditzak direlako azentugabeak eta esaldi bukaeran doinuaren (intonazioaren) maila oso baxua delako esaldi bukaeran (ikus Hualde et al., 1993, 1994 edo Elordieta, 1998 xehetasun gehiagorako). 
Oro har, azentu deribatua aditz nagusiaren aurre-aurrean dagoen hitzean kokatzen da, (2)-n bezala. Kontuan izanik euskaraz oro har aditz jokatuaren aurrean doan osagaia fokutzat har daitekeela (euskalaritzako terminologian, «galdegaitzat») -baina ez nahitaez, SOA ordena neutroan perpaus osoa izan baitaiteke fokua-, esan daiteke azentu deribatuak foku interpretazioa ematen duela. Badira, hala ere, konplexutasun batzuk azentu deribatuaren kokapen arauan. Hasteko, aditza trinkoa bada, azentua aditzean bertan kokatzen da, ez galdegaigunean dagoen sintagman, ikus (3):

(3) a. Gure lagunen alabia datór

b. *Gure lagunen alabiá dator

'gure lagunaren alaba dator'

(3)-n galdegaia [gure lagunen alabia] sintagma da, nahiz eta azentua aditz trinkoan egon. Kasu honetan, beraz, egitura prosodikoa eta sintaktikoa ez datoz bat.

Bigarrenik, perpausaren galdegaia baieztapena baldin bada (verum focus) partizipioak darama azentu deribatua (4)-ko adibidean bezala (Hualde et al., 1994, 61. orr.):

Zure lagunen alabia etorrí da

(2) eta (4) testuinguru pragmatiko desberdinetan erabiliko lirateke. (2) 'nor etorri da?' galderaren testuinguruan erabil daiteke edo baita informazio berria emateko ere. Bestalde, (4)-k proposizioa egia dela baieztatzen du.

Hemen aipatutako arazo horietaz ez dugu ezer esango. Aldiz, galdegaiaren azentuaren arauak daukan beste alderdi korapilatsu bat izango dugu aztergai; alegia, azentu deribatuaren kokapena menpeko perpausetan. A. Elordietak (2002) erakusten du menpekotasun motaren arabera, galdegaiaren azentua menpeko aditzaren aurrean kokatu daitekeela -ela konplementatzailea duten menpeko esaldietan, hitz edo sintagma hori fokua denean (5), baina beste konplementatzaile bat duten menpeko esaldietan hau ezin dela, eta, aitzitik, azentua aditz laguntzailea+konplementatzaileak osaturiko hitzean kokatzen dela (6). Beraz, nahiz eta galdera bat egon aurretik menpeko esaldiko subjektuari buruz, azentuera ezberdina dago bi esaldi motetan ${ }^{2}$ :

(5) a. Nor etorri dala esan dau?

b. Zure lagunen alabiá etorrí dalá esan dau

(6) a. Nor etorri dalako esan dau hori?

b. Zure lagunen alabia etorrí dalakó esan dau hori

2 Egia esan, bai (5)-n eta baita (6)-n ere, azentu bat dago aditz nagusiaren azken silaban eta beste bat aditz laguntzaile+konplementatzailearen azken silaban. Horregatik idatzi ditugu menpeko esaldiko bi aditzak beraien arteko gidoirik gabe. Espazio-arrazoiengatik ezin gara artikulu honetan aditz nagusiaren azentuaz aritu; menpeko esaldiko aditzaren aurre-aurrean dagoen hitzak azentu nagusia jaso dezakeen ala ez eta menpeko esaldien artean honen inguruan dagoen ezberdintasunaz asimetria aztertzera mugatuko gara. Nolanahi ere, ez genuke aipatu gabe utzi nahi Ortiz de Urbinak berak (1994)-ko lan batean ohartarazi zuela aditz nagusiak azentua jasotzen duela laguntzailea aditz nagusira klitizizatzen delako, hitz prosodiko bat osatuz. 
Badirudi - ela atzizkia daramaten perpaus konpletiboak bereziak direla. Menpeko perpaus hauetan menpeko aditzaren aurreko sintagmak hartzen du galdegaiaren azentua. Beste menpeko perpaus guztiekin, aldiz, galdegaiaren azentua aurreko sintagman ez, baizik eta menpeko aditz jokatuan kokatzen da (A. Elordieta, 2002; Arregi, 2006).

Artikulu honek bi helburu ditu. Alde batetik, enpirikoki baieztatu nahi dugu zein den galdegaiaren azentuaren kokagunea menpeko perpausetan, izari akustikoak aztertuz. Bigarrenik, azalpen sintaktiko bat proposatu nahi dugu ikusten dugun banaketarako.

\section{METODOLOGIA}

Hamar esaldi sorta eratu ditugu. Guztiak dira $n z$-galdera bati erantzuten dioten esaldiak, hau da, foku estua dutenak. Esaldi sinpleetan, foku estua edo galdegaia aditz nagusiaren aurre-aurrean kokatuko da (cfr. (7)). Menpeko esaldietan, foku estua menpeko aditzaren aurre-aurrean doa (cfr. (8)). Adibidez:

(7) a. Nóri ekarri dótzo erregalúa?

b. Umiarí ekarri dotzo erregalúa

(8) a. Nóri esan dau erregalúa ekarri dotzola?

b. Umiarí ekarrí dotzola erregalúa esan dau.

Horietako bostetan hitz guztiak lexikalki azentugabeak dira. Beste bostetan menpeko perpausaren aditzaren aurrean dagoen hitza lexikalki azentuduna da. Esaldi sorta edo talde bakoitzak zazpi esaldi ditu: perpaus sinple bat eta sei perpaus konplexu atzizki menderatzaile desberdinekin. (9)-n horren adibide bat ematen dugu (zerrenda osoa artikuluaren bukaeran jarri dugu, eranskinean):

(9) a. umiarí ekarri-dotzo erregalúa

b. umiarí ekarrí dotzola erregalúa esan dau

c. umiari ekarrí dotzolako erregalúa ipiñi da pozik

d. ía umiari ekarrí dotzon erregalúa pregunta dau

e. umiari ekarrí dotzonian erregalúa ipiñi da pozik

f. umiari ekarrí dotzon erregalúa da merkia

g. umiari ekarrí dotzonétik erregalúa dabill pozik

(9)-n mendeko aditzaren aurrean dagoen hitzak (umiari) azentua badarama, espero dugu tonu beherakada bat ikustea hurrengo silaban, Lekeitioko hizkeran azentua H*L kontornu baten bidez gauzatzen baita (G. Elordieta, 1998). Beraz, umiari hitzaren azken bokalaren tonua eta ekarri hitzaren lehen bokalaren tonua neurtzen baditugu, alde nabari bat aurkituko dugu printzipioz, ikus 1. irudia. Aldiz, umiari hitzak ez badu azenturik hartzen, bi silaben arteko tonu aldea askoz txikiagoa izango da, ikus 2. irudia. 


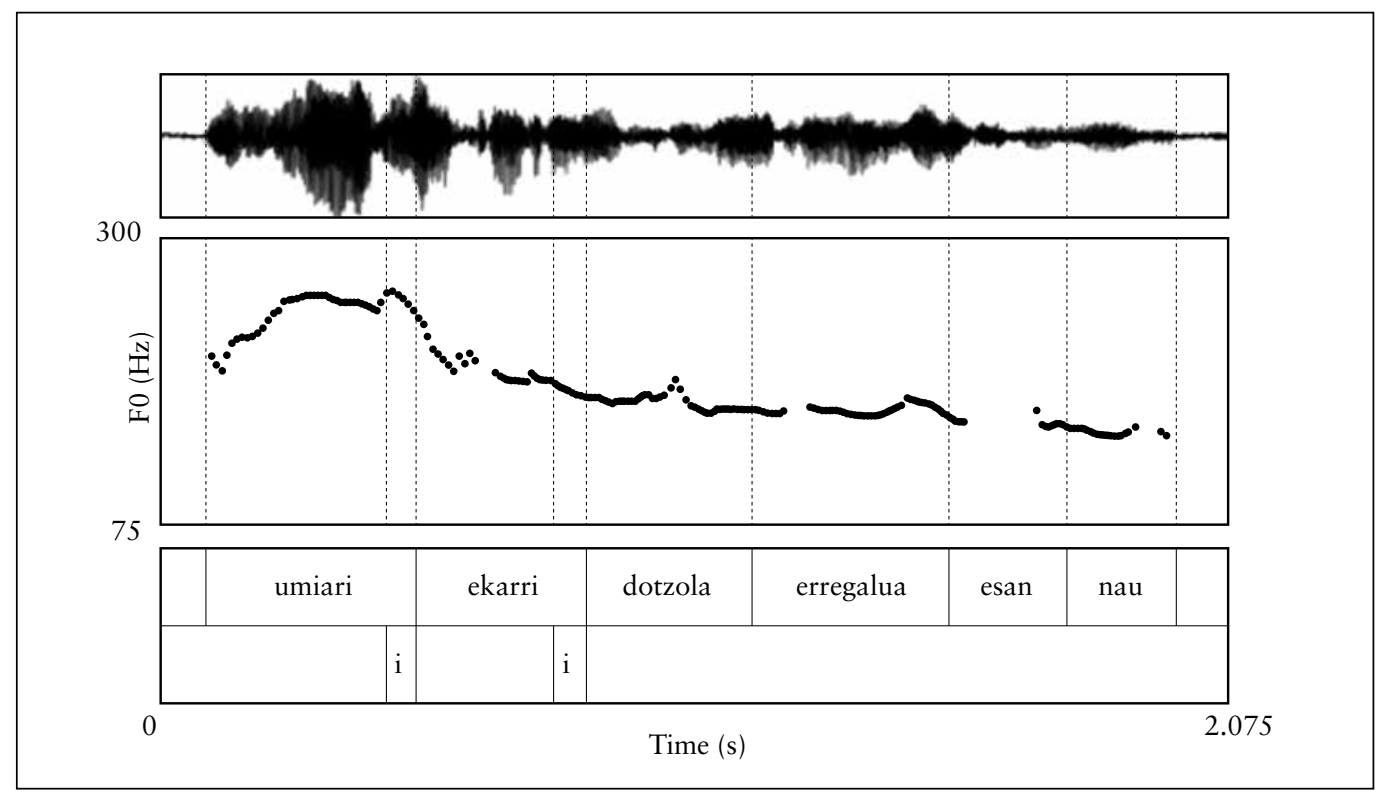

1. Irudia: umiari ekarrí dotzola erregalúa esan nau 'umeari ekarri diola erregalua esan dit'. Umiarí hitzak galdegaiaren azentua darama.

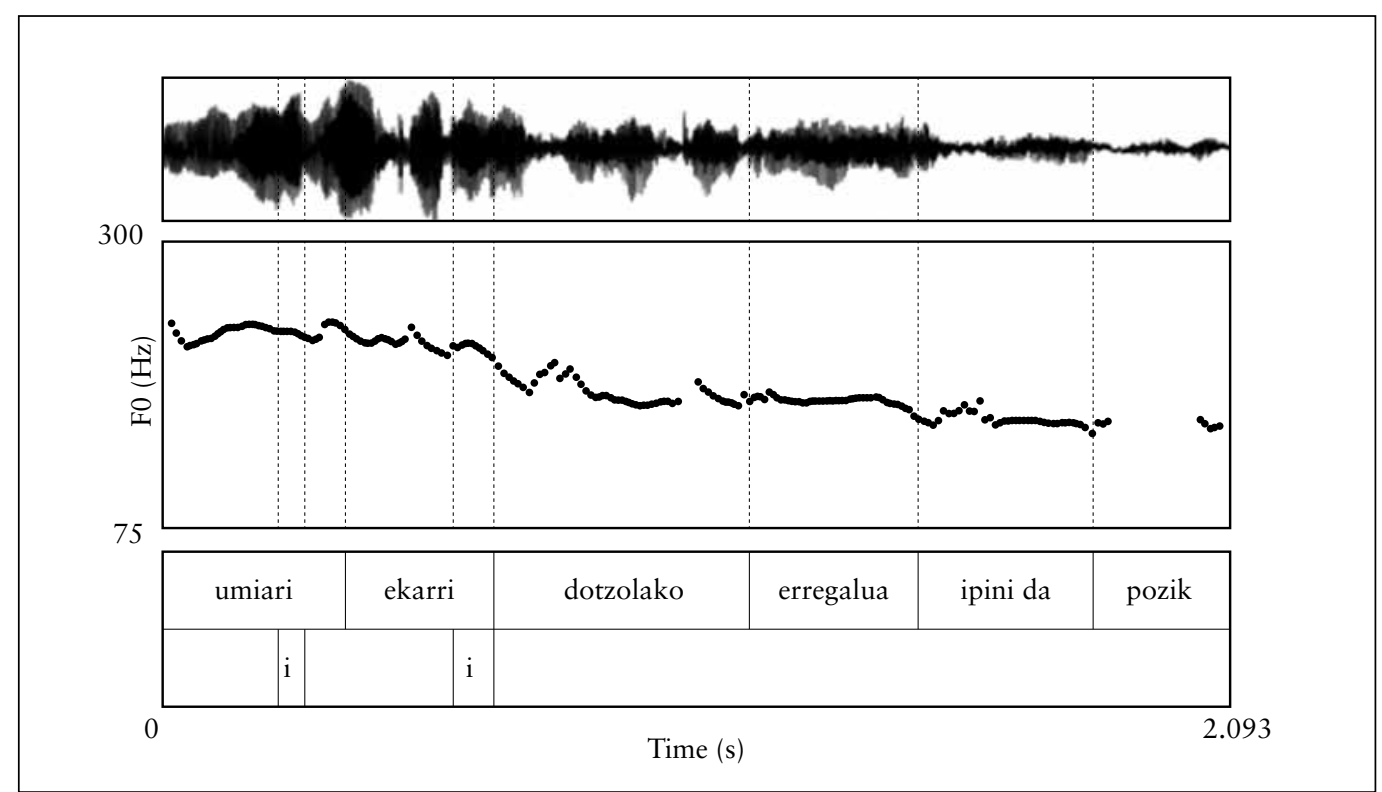

2. Irudia: umiarí ekarrí dotzolako erregalúa ipiñi da pozik 'umeari ekarri diolako erregalua ipini da pozik'. Umiari hitzak ez du azenturik.

Esan bezala, kontraste hau Bizkaiko iparraldeko doinu-azentuzko hizkeretan aurkitzen da. Hemen erabili ditugun adibideak lekeitierazkoak dira, baina Arregik (2006) ondarruerazko datuak aurkezten ditu. Guk, ebidentzia esperimentala jasotzeko, 
Lekeitioko hiru hiztuni eta Amorotoko beste hiztun bati eskatu diegu esaldi zerrenda osoa irakurtzeko bi aldiz, hurrenkera arbitrario batean (10 esaldi sorta x 7 esaldi x 2 errepikapen $\mathrm{x} 4$ hiztun $=560$ token). Lekeitioko hiztunak bi emakume eta gizon bat izan dira, 19-52 urte bitartekoak; bi goi-mailako ikasketadunak eta bat goi-mailako ikasketak egiten ari dena. Amorotoko hiztuna emakumezkoa izan da, 19 urtekoa, goi-mailako ikasketak egiten ari dena.

Analisi akustikoa PRAAT (Boersma \& Weenink, 2017) programaren bidez egin dugu. Textgrid-etan bi bokal segmentatu ditugu eskuz: galdegaigunean dagoen hitzaren bokal azentuduna eta partizipioaren azken bokala, 1-2 irudietan erakusten den bezala. Tonu (F0) neurketak automatikoki atera ditugu script edo programa berezi batekin.

Esan bezala, segmentatu ditugun bi silabetako F0 balioak konparatuz, diferentzia handiak espero ditugu lehen hitzak fonologikoki H"L azentu bat daramanean; hau da, (a) hitza lexikalki azentuduna denean eta (b) lexikalki azentugabea bada ere galdegaiaren azentua jasotzen duenean. (b) kasuan perpaus sinpleak eta -ela atzizkia duten konpletiboak ditugu. Beste kasu guztietan aldea askoz txikiagoa izan beharko litzateke, hipotesiari jarraituz: lehen hitza lexikalki azentugabea denean eta menpeko aditz laguntzaileak -elako, -en, -enian edo -enétik atzizkia daramanean.

Analisi estatistikoa egiteko R/Rstudio (R Core Team, 2017; R Studio Team, 2017) erabili dugu.

\section{EMAITZAK}

Emaitzak irudietan aurkezteko esaldiak bi taldetan banatu ditugu aditzaren aurrean dagoen hitzaren azentuera lexikalaren arabera ${ }^{3} .3$. irudian galdegaigunean dagoen hitza azentugabea da. Ardatz bertikalean bi hitzen arteko aldea Hz-tan erakusten da. Ikusten den bezala, neurketa honek alde batetik perpaus sinpleak eta -ela daukaten konpletiboak jartzen ditu eta bestetik beste esaldi mota guztiak. Ez dago gainjartzerik. Bi bokalen arteko batez besteko aldea (lehen hiztuna/bigarren hiztuna) 65,9/62,2 Hzkoa da esaldi sinpleetan eta 54,2/49,4 Hzkoa -ela duten konpletiboetan. Beste esaldi mota guztietan, batez bestekoak askoz txikiagoak dira: $i a=-3,7 / 0,7$; elako $=1,6 / 3,6$; -enétik $=6,5 / 4,2 ;$-enian $=3,3 / 1,3$; erlatibozkoak = 0,2/1,3. Hipotesia, beraz, baieztatu dugu.

3 Lau hiztun grabatu eta aztertu baditugu ere, zoritxarrez ez dugu astirik izan datu guztiak segmentatzeko. Hemen bi hiztunen emaitzak baino ez ditugu analisi estatistikoan sartuko. Datuak kuantitatiboki oso antzekoak dira bi hiztunen artean. Lehen hiztunak ez zekien gure hipotesia zein zen, eta bigarren hiztuna egileetariko bat da (biak emakumeak). F0 kontornuak ikusita argi dago beste bi hiztunek ere kontraste berberak egiten dituztela, galdegaiaren azentua posiblea delarik -ela duten menpeko esaldietako aditzen aurrean baina ez beste konplementatzaileak dituzten menpeko esaldietan. Lekeitioko hiztunen eta Amorotoko hiztunaren arteko ezberdintasun bakarra da Amorotokoak azentu deribatua hitzaren azkenaurreko silaban ezartzen duela, Markinan eta Ondarroan egiten den bezala (Hualde, 1997, 201-221. orr.). 

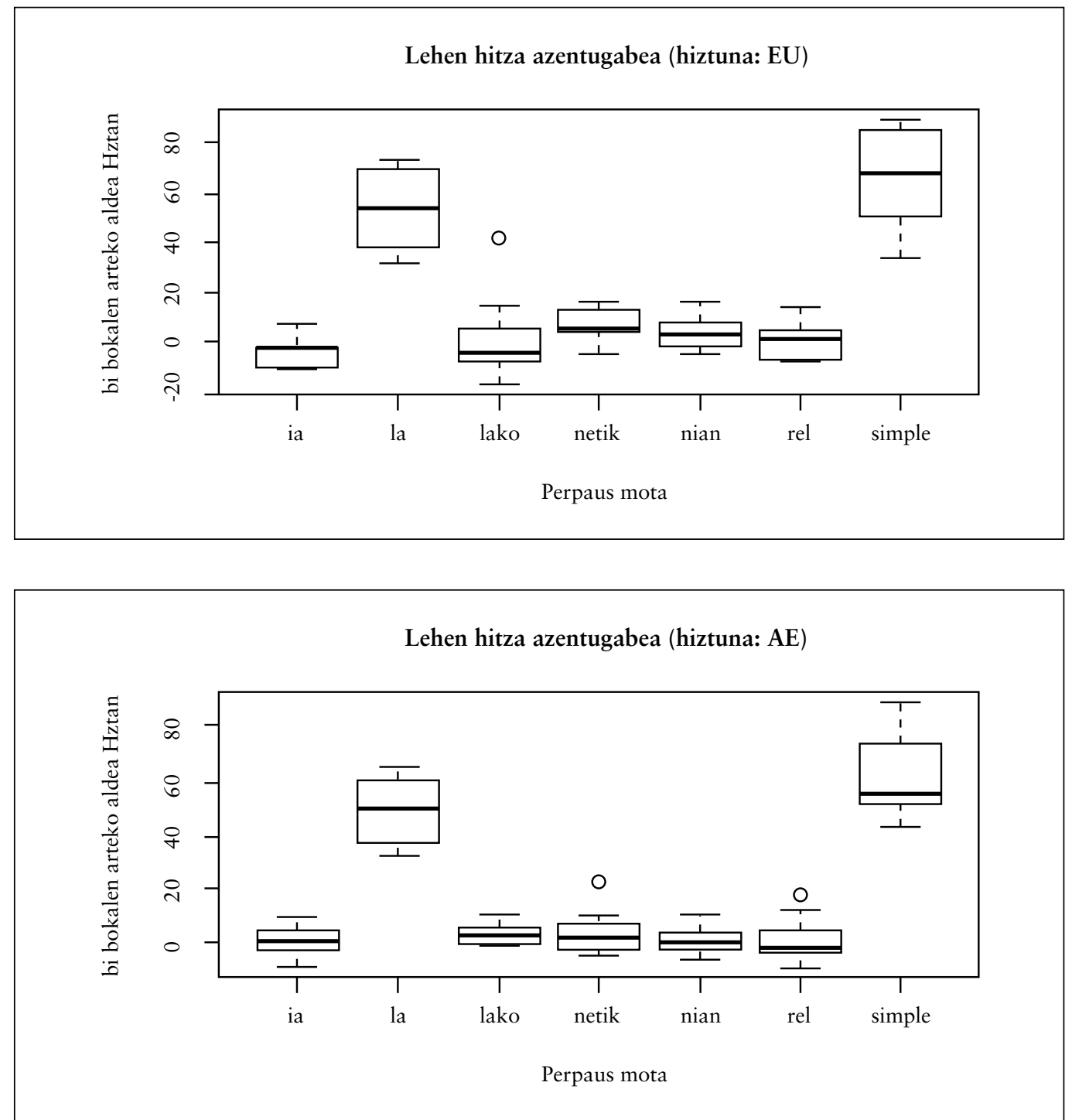

3. irudia: neurtutako bi bokalen arteko aldea Hz-tan, aditzaren aurrean dagoen hitza lexikalki azentugabea denean. (Bi hiztun).

Egoera guztiz desberdina da galdegaigunean dagoen hitzak (lehen hitza gure neurketan) azentu lexikala daukanean. 4. irudian lehen aditzak -elako lokailua darama, 2. irudian bezala, baina aditzaren aurrean dagoen hitza azentuduna da (umiári 'umeei'). 


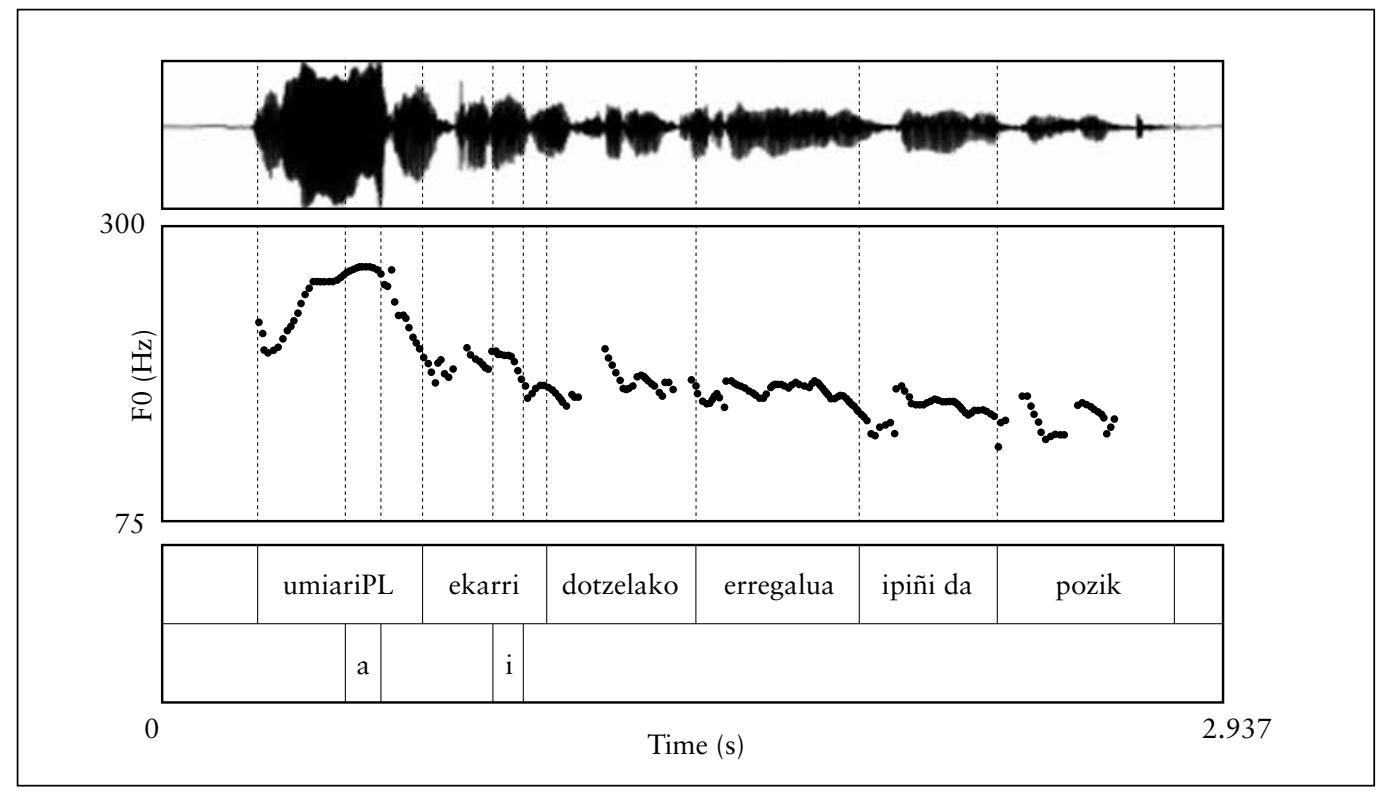

4. irudia: umiári ekarrí dotzeláko erregalúa ipiñi da pozik 'umeei ekarri dielako erregalua ipini da pozik'. Umiári hitza azentuduna da.

Kasu honetan ' $i a$ ' duten esaldiak alde batetik doaz, oso diferentzia txikiekin (batez bestekoa, lehen hiztuna/bigarren hiztuna: 11,5/12,9 Hz), eta beste talde batean beste esaldi guztiak alde askoz handiagoekin, $50 \mathrm{~Hz}$ ingurukoak bi hiztunentzat (batez bestekoak: -ela $=55,8 / 59 \mathrm{~Hz}$; - elako $=52,2 / 63,8 \mathrm{~Hz}$; -enétik $=48,5 / 57,3 \mathrm{~Hz}$; -enian = 48,1/65,5 Hz; erlatibozkoak = 49,5/64 Hz; eta sinpleak = 65,9/73,3 Hz).

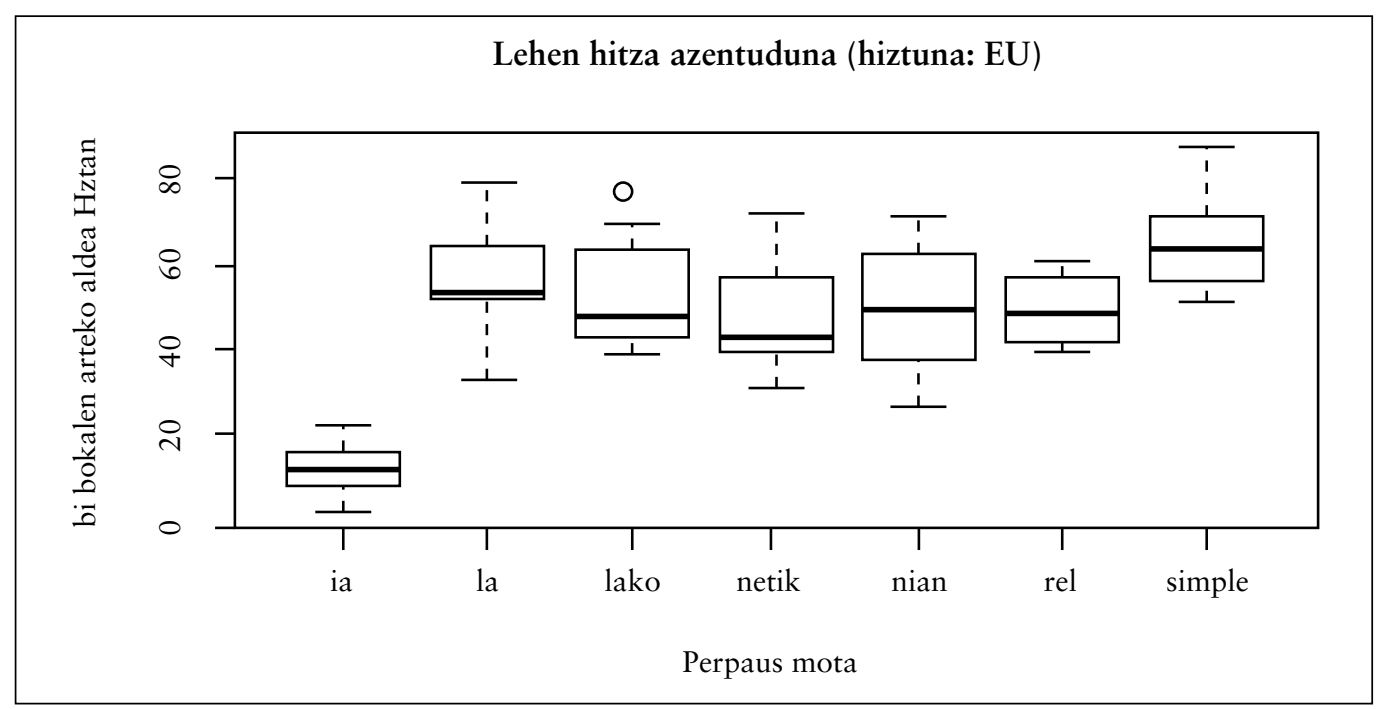




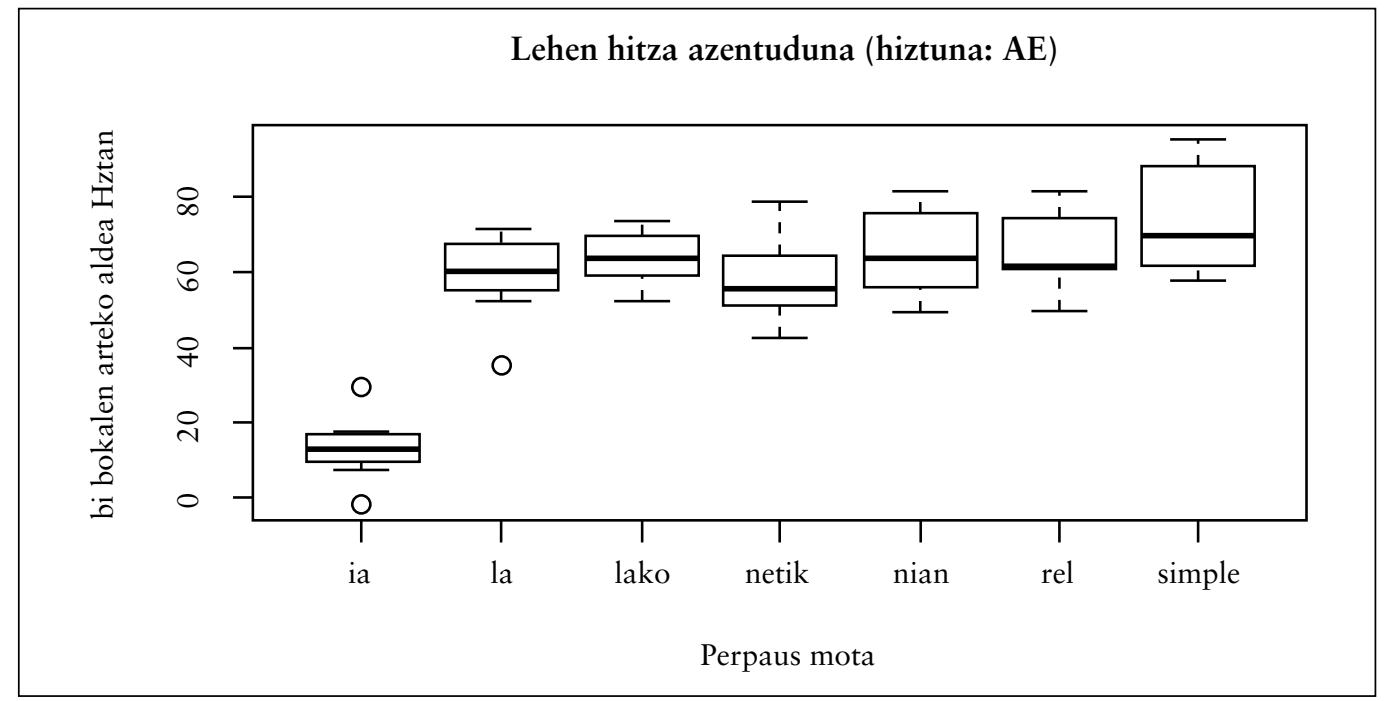

5. irudia: neurtutako bi bokalen arteko aldea Hz-tan, aditzaren aurrean dagoen hitza lexikoki azentuduna denean. (Bi hiztun).

Hemen gertatzen dena da ía partikula menperatzailea azentuduna dela, ikus 6. irudia. Arrazoi horregatik kasu honetan gure lehen neurketa esaldiaren bigarren azentuari dagokio.

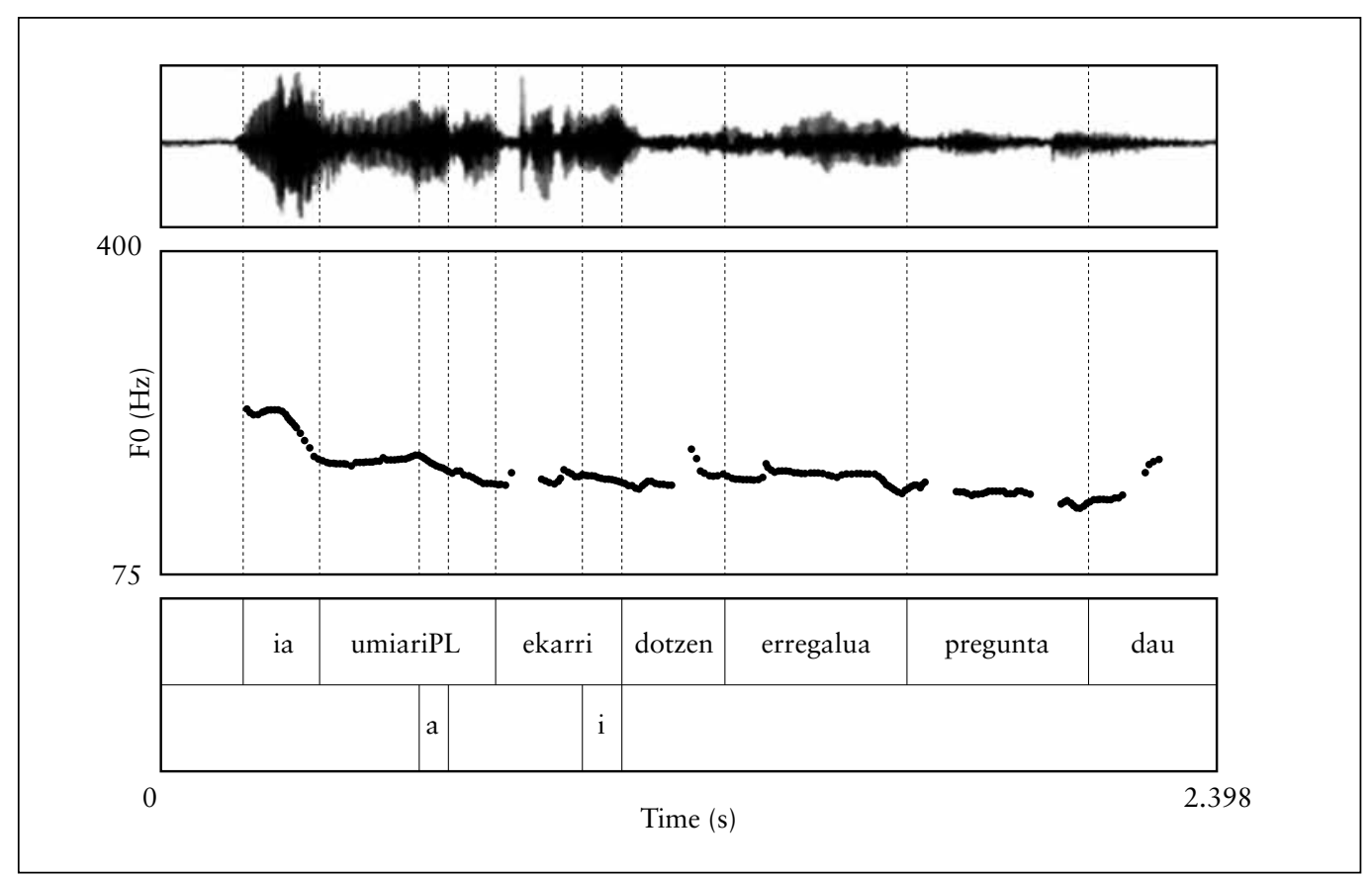

6. irudia: ía umiári ekarrí dótzen erregalúa pregunta dan 'ea umeei ekarri dien erregalua galdetu du'. Ía hitza azentuduna da eta hurrengo azentua, umiári hitzean, beheratu egiten du. 
Beraz, hemen interesatzen zaigun kontrastea ez da ikusten galdegaigunean dagoen hitza lexikoki azentuduna denean, baina bai, eta oso argi, hitz hori azentugabea denean. Galdera da zergatik - ela atzizkia daramaten perpaus konpletiboak bereziak diren eta haien barruko hitz azentugabeak soilik eraman dezakeen galdegaiaren azentua.

Analisi estatistikorako datu guztiak kontuan hartu genituen (guztira 280 esaldi) eta hiru mailako aldagai bat sortu genuen (Esaldi Mota): esaldi sinpleak, konpletiboak eta beste menpeko esaldiak. Neurtutako bi bokalen f0-ko aldeen efektu mistoko erregresio analisi bat egin genuen $\mathrm{R}$ programaren bitartez (R Core Team, 2017) lme4 paketeko lmer funtzioarekin (Bates, Maechler, Bolker \& Walker, 2015) (p-ren balioak afex paketearekin lortu ziren, Singmann, Bolker, Westfall \& Aust, 2017). Faktore tinko bezala Esaldi Motaren eta Azentu Motaren arteko interakzioa aukeratu genuen, non Esaldi Mota faktoreak hiru maila dituen eta Azentu Mota faktorea lehen hitzari dagokion (azentuduna edo azentugabea den). Gure hiztunek esaldiak bi aldiz errepikatu zituztenez, errepikapena ere sartu genuen faktore tinko bezala. Faktore aleatorio bezala hiztuna eta esaldiaren lehen hitza sartu ziren. Hau da, erregresioak (lmer) honako egitura du: f0diff $\sim$ EsaldiMota * AzentuMota + Errepikapena (1lhiztun)+(1lhitz).

Hurrengo konparaketen emaitzak estatistikoki esanguratsuak ziren erregresio horretan: konpletiboak vs beste menpekoak (Est. $=-10.08, \mathrm{t}=-2.77, \mathrm{p}<0.01$ ) eta bere interakzioa Azentu Mota faktorearekin (Est. $=-39.75 \mathrm{~Hz}, \mathrm{t}=-7.61, \mathrm{p}<0.001$ ); konpletiboak vs sinpleak (Est. $=12.16 \mathrm{~Hz}, \mathrm{t}=2.58, \mathrm{p}<0.05)$. Errepikapenak ez zuen efekturik.

Beraz, gure analisiaren emaitzek erakusten dute -ela konplementatzailea duten esaldien eta beste menpeko esaldien arteko F0-ko aldeak estatistikoki esanguratsuak direla eta diferentzia horiek askoz handiagoak direla galdegaian dagoen hitza azentugabea denean. Bigarrenik, -ela konplementatzailea duten esaldien eta esaldi sinpleen artean dauden aldeak ere esanguratsuak dira.

\section{ANALISI SINTAKTIKOA}

\subsection{Kontrastea: -ela vs. beste konplementatzaileak}

Gorago aipatu dugunez ((5), (6) adibideak), azentu nagusiaren kokapena aldatu egiten da menpeko perpausa motaren arabera (A. Elordieta, 2002; Arregi, 2006). A. Elordietak ohartarazi zuen asimetria bat zegoela azentu nagusiaren kokapenean, menpeko perpausa osagarri perpausa izan -i. e., -ela konplementatzaileduna- ala adjunktua $-i$. e., -elako/-enean konplementatzaileduna- (ikus (9)-ko adibideak), eta proposatu zuen asimetriak lotura zuela egitura sintaktikoarekin, adjunktuak irla sintaktikoak direlako, eta azentu nagusiaren ezarketak ezin duelako irla barruan eragin ${ }^{4}$.

4 Arregik (2006) beste analisi bat proposatzen du, baina funtsean Elordietak (2002) aztergai dituen perpaus mota berak aztertzen ditu, eta kontraste bera dagoela berresten du. 
Hala ere, menpeko perpaus gehiagori erreparatuz gero, berehala konturatuko gara banaketa nagusia ez dela gertatzen osagarri perpausak vs. adjunktu perpausen artean, baizik eta-ela perpausak vs.--en/-enean/-enétik... perpausen artean datzala. Hau da, gakoa menperatzailearen hautaketan bertan datza, ez horrenbeste menpeko perpausaren funtzio sintaktikoan. Izan ere, zehargalderak osagarri perpausak izan arren, desberdin jokatzen dute azentu nagusiaren kokapenari dagokionez, adjunktu perpausekin lerrokatuz. Hurrengo adibideek erakusten duten bezala, (11)-ko eta (12)-ko menpeko esaldiek portaera berdina dute, nahiz eta (11)-koak adjunktu funtzioa izan eta (12)-ko zehargaldera esaldi nagusiko aditzaren osagarria izan ${ }^{5}$ :

(10) [Zure lagunen alabiá etorrí dalá] esan dau

(11) [Zure lagunen alabia etorrí dalakó] esan dau hori

(12) [(ía) zure lagunen alabia etorrí dán] pregunta nau

Gauza bera gertatzen da -en menderagailua hautatzen duten bestelako izen-predikatu perpausekin ere, dudia daukát zeure alabia etorríko (ete) dan motakoekin, alegia. Hauetan ere aditz jokatuaren aurreko osagaiak ezin du azentua jaso, espero bezala gure hipotesia bide onetik badoa. Era berean, hurrengo adibideek erakusten dute foku azentuaren banaketa ez dagoela zuzenean lotuta aditz nagusiaren izaerarekin, hots, esan motakoa den (hizkuntza germaniarretan MCP edo perpaus nagusiaren itxurako mendekoak hartzen dituena) edo faktiboa $\mathrm{den}^{6}$ :

(13) a. [etxe barrijá erosí dozulá] ahaztu jat

b. [etxe barrijá erosí dozulá] jakin dot

(10)-(13)-ko datuek aditzera ematen dutenez, soilik -ela-dun menpeko osagarri perpausaren barneko argumentuak jaso dezake azentua; beste kasuetan aditz laguntzailean kokatzen da. Ondoko lerroetan asimetria hauen berri eman dezakeen proposamen bat aurkeztu nahi dugu, azken urteetan sintaxiaren eta PF-ren arteko interfazeaz diharduten hainbat lanetan irekitako ildotik. Zehazki, azentu nagusia ezartzen duen arau fonologikoa sintaxian zikloak bereizten dituen faseekin elkarreraginean dagoela proposatuko dugu (Legate, 2003; Adger, 2007; Kratzer \& Selkirk, 2007; Kahnemuyipour, 2009; Downing, 2010; Ahn, 2015).

5 Zuzentzaile batek iradokitzen du beharbada manten daitekeela Elordietak (2002) azentua jaso ezin izatea irla sintaktikoak izateari leporatzen zion ideia, aintzat hartuta -en zehargalderetan operatzaile baten mugimendua gertatzen dela. Datu gehiagorekin aztertzeko kontua den arren, ez dugu uste adjunktu perpausek eta -en zehargalderek irla-efektu berberak erakusten dituztenik; izan ere, ezaguna da zehargalderak irla ahulak direla ateraketa kontuetarako (eta, ondorioz, hiztunen arteko barne-aldakortasun gehiago dago), adjunktu perpausek irla sendoen efektuak erakusten dituzten bitartean. Bestalde, azken urteotan eztabaida bizia dago «irla efektuak» benetan sintaxiaren kontuak diren, ala kontu semantiko-pragmatikoa den (besteak beste, Szabolcsi, 2006; Boeckx, 2012).

6 Eskerrak eman nahi dizkiogu zuzentzaile anonimoetako bati datu hauek gure analisira batu ditzagun iradokitzeagatik. 


\subsection{Azentua eta faseak}

Ezaguna denez, hainbat lanetan argudiatu da perpauseko azentu nagusiaren kokapena (NSR) ez dela 'erabakitzen' eratorpen sintaktiko osoa burutu arte, baizik eta zatika, zikloka, gertatzen dela (Bresnan-en (1971) aspaldiko ideia garatuz). Adger-ek (2007) eta Kratzer-rek eta Selkirk-ek (2007) diotenez (ikus baita Legate, 2003; Kahnemuyipour, 2009), hipotesirik sinpleena da pentsatzea azentu ezarketaren eremu fonologikoak baduela bere baliokidea eremu sintaktikoan: fasea (Chomsky, 2001, 2004, 2006). Uriagerekaren (1999) Aboskatze Anizkuna (Multiple Spell-out) analisian oinarrituz, ideia da azentu nagusia ziklikoki ezartzen dela fase bakoitza Ahoskatze-gunera (Spell-out) bidaltzen den bakoitzean. Azterbide honetan lan egiten duten lanetan estandarra denez, Ahoskatze-gunera bidaltzen dena fase-buruaren osagarria da bakarrik; burua bera eta haren espezifikatzailea hurrengo fasera arte 'erabilgarri' daude eratorpen sintaktikorako. Horrek esan nahi du azentuaren ezarketak fase-buruaren osagarrian dauden elementuei bakarrik eragingo diela (Legate, 2003; Adger, 2007; Ahn, 2015).

Era berean, garrantzitsua da azpimarratzea azterbide honetan Ahoskatzea fasearen eremu barruko mugimendu guztiak egin ondoren gertatzen dela. Ondorioz, azentu nagusia ezartzen duen arau fonologikoak mugimenduen ondoren geratzen diren osagaiei eragingo die fase bakoitzean. Ikusiko dugunez, mugimendua gertatu den ala ez onartzeak ondorioak izango ditu aztergai dugun -ela vs. -en/-enétik/-enean/-elako kontrastea azaltzeko.

Azentu nagusia nola ezartzen den iragartzeko, NSR erregelaren bertsio hau erabiliko dugu, Adgerren (2007) formulazioa egokituz':

(14) a. Errepikatu azentu nagusia hurrengo zikloetan (faseetan)

b. Azentua duen osagairik ez badago, eskuinaldean dagoen osagaiarena islatu

Azkenik, aS eta JokS ${ }^{8}$ (= CP Chomskyren 2001, 2004 eta ondoko lanetan) sintagmez gain, PosS ere fasea dela (Abels, 2003, 2012) onartuko dugu.

Ikus dezagun nola eratortzen dugun aztergai ditugun menpeko perpausen azentuaren gauzapena. Apur bat sinplifikatuko ditugu goragoko perpausak, deribazioa errazteko asmotan:

(15) [Zure alabiá etorrí dalá] esan dau

(16) [(ia) zure alabia etorrí dán] pregunta nau

(17) [Zure alabia etorrí dalakó] esan dau hori

7 Adger $(2007,28$. orr.): a. Project the highest stress to the next line of the grid.

b. In the absence of a highest stress, project the rightmost. [cfr. Gussenhoven, 1983].

8 Hemen Jon Ortiz de Urbinari $(1999,2008)$ jarraitzen diogu Rizzi-k (1997) abiatutako Konplementatzaile Sintagmaren zatiketaren analisia euskarara ekarriz, hau da, JokS = Jokatua Sintagma, buru azkena da, eta haren goragoko kategoria funtzionalak (FokuS, TopS eta IndarS) buru lehenak. 
Has gaitezen -ela konplementatzailedun perpausen deribazioarekin ${ }^{9}$. Chomskyri (2001) jarraituz, aditz ezakusatiboetako aS 'akastuna' da eta ez da fasetzat hartzen. Beraz, deribazioak aurrera egiten jarraituko du ezer Ahoskatu gabe hurrengo fasera arte: 'etorri' aditza lehenik $a$ aditz txikira igoko da, gero Denb txertatuko da, aditza bertara mugituko da eta [zure alabiá] DenbS-ren espezifikatzailera igoko da. Hurrengo, Jokatua fase-burua txertatuko da, [A-Denb] Jok burura igoko da, eta honen osagarria den DenbS bidaliko da Ahoskatze-gunera. DenbS-n [zure alabiá] bakarrik dago, eta berak jasotzen du azentu nagusia menpeko perpausaren barruan.

$$
\left[_{\text {Joks }}\left[\text { Denbs } \text { zure alabiá } t\left[{ }_{a S} t t\right]\right] \text { etorrí dala }\right]
$$

-en eta -elako konplementatzailedun perpausei dagokienez, eratorpenak -ela perpausekin proposatu dugun modura lan egiten du, desberdintasun batekin: Kayne-k (2000) frantseseko eta beste hizkuntza batzuetako konplementatzaileei buruz iradokitakoari jarraituz, -en, -enétik, -elako motako konplementatzaileak posposiziodun konplementatzaileak direla proposatuko dugu, ondoko egitura proposatuz:

$$
\left[{ }_{\text {Poss }}\left[{ }_{\text {JokS }}\left[{ }_{\text {DenbS }}\right]\right]\right]
$$

Era berean, Kaynerekin $(2000,2005)$ batera proposatuko dugu posposiziodun Konp honek DenbS-ren mugimendua erakartzen duela. Oinarri hauek aintzat hartuz, -ela duten menpeko perpausekin dagoen aldea honetan datza: Pos fase-burua txertatzen denean, Jokatua buruan dagoen osagaia Pos-ra mugitzen da, eta DenbS Pos-ren espezifikatzailera. Hartara, PosP fasearen osagarria (JokS) Ahoskatze-gunera bidaltzen denean, osagarri hau hutsik dago, ez du izaera fonologikorik (aditz jokatuaren eta DenbSren aztarnak bakarrik daudelako). Hortaz, (14b)-ren arabera, PosP osoan eskuinaldean dagoen elementuak (aditz jokatuak) jasoko du azentu nagusia. PosP fasearen ertzean (espezifikatzailean) dagoen DenbS ez da konputatzen Ahoskatze-gunerako ${ }^{10}$.

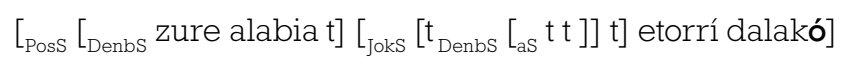

9 Lanaren orrialde-kopuruaren muga dela eta, hemen aurkezten dugun eratorpenean egitura nahiko sinplifikatu dugu, eta tradizionaltzat jo daitekeen buru-mugimenduaren azterbidea onartu dugu (Ortiz de Urbina, 1989; Laka, 1990; Elordieta, 2001). Zuzentzaile batek ohartarazten duenez, aldiz, azterbide honek baditu arazo batzuk (besteak beste, morfema ebidentzialak aditzaren eta laguntzailearen artean agertzea, edota ezeztapenaren hurrenkera), eta iradokitzen du arazoak saihesteko gure proposamenari eutsi dakiokeela onartuz gero aditza Aspektu burura mugitzen dela lehenik, eta hau postposizioduna baldin bada, haren osagarria den [zure alabiá] sintagmak jasoko duela azentua, espero bezala. Iradokizun honek xehekiago aztertzea merezi du, dituen ondorioengatik, baina nolanahi ere, garrantzitsua da azpimarratzea ez duela zalantzan jartzen gure proposamenaren muina edo izpiritua.

10 Proposamen honek, gainera, lagun gaitzake ulertzen zergatik erakusten dituzten irla efektuak (batzuk ahulak, besteak sendoagoak) posposiziodun konplementatzailea daramaten perpausek:

(i) ?/?? Nori galdetu duzu [t saria eman dioten]?

(ii) *Nor abiatuko zarete mendira [t etorriko denean]?

Izan ere, egitura horietan DenbS P-ren espezifikatzailean badago, ateraketa nekezagoa gertatzea espero izatekoa da. 


\section{ONDORIOAK}

Lan honen abiapuntua eta xedea menpeko perpausetako azentu nagusiaren kokapena aztertzea izan da. Zehazki, aditz aurreko hitz azentugabeei erreparatu diegu, horietan soilik ikus daitekeelako -ela menpeko perpausen eta -en, -enétik, -elako, -enean menpeko perpausen arteko asimetria interesgarria azentu deribatuaren kokapenari dagokionez. Alde batetik enpirikoki baieztatu nahi izan dugu asimetria benetan gertatzen den, eta bestetik kontraste honi azalpena bilatu nahi izan diogu. Emaitzek erakusten dutenez, kontrastea egiazkoa da; - ela menpeko perpausaren aurreko hitz azentugabeek azentua jaso dezakete, baina aztertu ditugun beste menpeko perpausen aurreko hitz azentugabeek ez. Hauetan, azentua aditz laguntzaileak eta konplementatzaileak osatzen duten hitz prosodikoan kokatzen da.

Asimetriaren berri emateko, PF-ren eta sintaxiaren arteko harremana aztertzen duten hainbat lanen ildotik (Legate, 2003; Adger, 2007; Kratzer \& Selkirk, 2007; Kahnemuyipour, 2009; besteak beste), azentuaren ezarketaren eremu fonologikoa fase sintaktikoa dela proposatu dugu, eta hala, ziklikoki, faseka, erabakitzen dela. Faseak $a$, Jok, eta $P$ direla aintzat hartuz, proposatu dugu eratorpen sintaktikoan eratutako fase bat Ahoskatze-gunera bidaltzen den bakoitzean azentu nagusiaren ezarketaren araua aplikatzen dela, eta hurrengo fasean berriro, perpaus osoa islatu arte. Adgerren (2007) formulazioa (14)-n egokitu dugu, eta menpeko perpausetako hitz azentugabeek erakusten duten jokabide desberdina azaltzeko - ela konplementatzailedun perpausek eta besteek egitura desberdina dutela proposatu dugu. Zehazki, iradoki dugu -ela izan ezik, beste konplementatzaileak postposiziodun konplementatzaileak direla, eta Kayneri (2000) jarraituz, Konp honek DenbS-ren mugimendua erakartzen duela bere espezifikatzailera. Horrela, azentuaren ezarketak fase-buruaren osagarrian dauden elementuei bakarrik eragiten badie (Legate, 2003; Adger, 2007; Ahn, 2015), arau honek ez du «ikusten» espezifikatzailean dagoena, eta, horrenbestez, posposiziodun konplementatzailea duten menpekoetan (14b) aplikatzen da eta eskuinaldean dagoen aditz jokatuak jasoko du azentu nagusia. -ela konplementatzailea, aldiz, ez da posposizioduna, eta, ondorioz, DenbS ez da mugituko, eta aditzaren aurreko hitzak jasotzen du azentu nagusia. 


\section{ERREFERENTZIAK}

Abels, K. (2003). Successive cyclicity, anti-locality, and adposition stranding (doktorego tesia). University of Connecticut.

Abels, K. (2012). Phases: an essay on cyclicity in syntax. Berlin eta Boston: Walter de Gruyter.

Adger, D. (2007). Stress and phasal syntax. Linguistic Analysis, 33, 238-266.

Ahn, B. (2015). There's nothing exceptional about the Phrasal Stress Rule. ling.auf.net/ lingbuzz/002458.

Arregi, K. (2006). Stress and islands in Northern Bizkaian Basque. Anuario del Seminario de Filología Vasca «Julio de Urquijo», 40, 81-106.

Bates, D., Maechler, M., Bolker, B. \& Walker, S. (2015). Fitting linear mixed-effects models using lme4. Journal of Statistical Software, 67, 1-48. doi:10.18637/ jss.v067.i01

Boeckx, C. (2012). Syntactic islands. New York: Cambridge University Press.

Boersma, P. \& Weenink, D. (2017). Praat: Doing phonetics by computer, 6.0.30 bertsioa. www.praat.org.

Bresnan, J. (1971). Sentence stress and syntactic transformations. Language, 47, 257281.

Chomsky, N. (2001). Derivation by phase. In M. Kenstowicz (arg.), Ken Hale: A life in language (1-52. orr.). Cambridge, MA: MIT Press.

Chomsky, N. (2004). Beyond explanatory adequacy. In A. Belletti (arg.), The cartography of syntactic structures: vol. 3. Structures and beyond (104-130. orr.). Oxford: Oxford University Press.

Chomsky, N. (2008). On phases. In R. Freidin, C. P. Otero \& M. L. Zubizarreta (arg.), Foundational issues in linguistic theory: Essays in honor of Jean-Roger Vergnaud (133-166. orr.). Cambridge, MA: The MIT Press.

Downing, L. (2010). An edge-based approach to the alignment of syntactic phases and prosodic phrases. In N. Vincent \& L. Mycock (arg.) The prosody-syntax connection. Transactions of the Philological Society, 108, 352-369.

Elordieta, A. (2001). Verb movement and constituent permutation in Basque (doktorego tesia, Universiteit Leiden). Utrecht: LOT. (LOT Dissertation Series, 47).

Elordieta, A. (2002). On the (im)possibility of prosodic focus marking in embedded contexts in Northern Bizkaian Basque. In X. Artiagoitia, P. Goenaga \& J. Lakarra (arg.), Erramu Boneta. Festschrift for Rudolf PG de Rijk (153-177. orr.). Bilbao: University of the Basque Country. (ASJU-ren Gehigarriak, 54).

Elordieta, G. (1998). Intonation in a pitch-accent variety of Basque. ASJU, 32, 511-69.

Gussenhoven, C. (1983). A semantic analysis of the nuclear tones of English. Bloomington (Indiana): Indiana University Linguistics Club.

Hualde, J. I. (1997). Euskararen Azentuerak. Donostia eta Bilbo: Gipuzkoako Foru Aldundia eta Euskal Herriko Unibertsitatea. (ASJU-ren Gehigarriak, 42).

Hualde, J. I., Elordieta, G. \& Elordieta, A. (1993). Focalización y prosodia en vascuence vizcaíno. ASJU, 26, 731-749.

Hualde, J. I., Elordieta, G. \& Elordieta, A. (1994). The Basque dialect of Lekeitio. Donostia: Gipuzkoako Foru Aldundia. (ASJU-ren Gehigarriak, 34). 
Jun, S-A. \& Elordieta, G. (1997). Intonational structure of Lekeitio Basque. In A. Botinis, G. Kouroupetroglou \& G. Carayiannis (arg.), Intonation: Theory, models and applications. Proceedings of an ESCA Workshop (193-196. orr.). Athens.

Kahnemuyipour, A. (2009). The syntax of sentential stress. Oxford: Oxford University Press.

Kayne, R. (1999). Prepositional complementizers as attractors. Probus, 11, 39-73. [Berrargitaratua: Kayne, R. (2000). Parameters and universals (282-313. orr.). Oxford: Oxford University Press].

Kayne, R. (2005). Prepositions as probes. In R. Kayne, Movement and silence (85104. orr.). Oxford: Oxford University Press.

Kratzer, A. \& Selkirk, E. (2007). Phase theory and prosodic spellout: The case of verbs. The Linguistic Review, 24, 93-105.

Laka, I. (1990). On the nature of functional categories and projections (doktorego tesia). MIT.

Legate, J. A. (2003). Some interface properties of the phase. Linguistic Inquiry, 34, 506-516.

Ortiz de Urbina, J. (1989). Parameters in the grammar of Basque. Dordrecht: Foris.

Ortiz de Urbina, J. (1994). Verb-initial patterns in Basque and Breton. Lingua, 94, 125-153.

Ortiz de Urbina, J. (1999). Focus in Basque. In G. Rebuschi \& L. Tuller (arg.), The grammar of focus (311-334. orr.). Amsterdam/Philadelphia: John Benjamins. [Euskarara moldatua: J. Ortiz de Urbina. (2008): Indar sintagmak, Foku sintagmak eta ezkerraldeko buruak euskaran. In I. Arteatx, X. Artiagoitia eta A. Elordieta (arg.), Antisimetriaren hipotesia vs. Buru parametroa: euskararen oinarrizko egitura ezbaian (51-68. orr.). Bilbo: EHU].

R Core Team. (2017). R: A language and environment for statistical computing. Viena, Austria: R Foundation for Statistical Computing. Hemendik hartua: https://www.R-project.org/.

RStudio Team. (2016). RStudio: Integrated Development for R. RStudio, Inc. Boston, MA. Hemendik hartua: http://www.rstudio.com/.

Rizzi, L. (1997). The fine structure of the left periphery. In L. Haegeman (arg.), Elements of grammar: Handbook of generative syntax (281-337. orr.). Dordrecht: Kluwer.

Singmann, H., Bolker, B., Westfall, J. \& Aust, F. (2017). afex: Analysis of Factorial Experiments. R package version 0.18-0, 2017. CRAN.R-project.org/ package $=$ afexT.

Szabolcsi, A. (2006). Weak and strong islands. In M. Everaert \& H. van Riemsdijk (arg.), The Syntax Companion (479-531. orr.). Oxford: Blackwell.

Uriagereka, J. (1999). Multiple spell-out. In S. D. Epstein \& N. Hornstein (arg.), Working minimalism (pp. 251-282). Cambridge, MA: MIT Press. 


\section{ERANSKINA}

[Azentu markak hiztunek ahoskatutakoa islatzeko dira. Ez ziren azentu markak jarri hiztunei aurkeztutako esaldietan, hiztunen ekoizpena ez baldintzatzeko. Azentu markak bakarrik singularra eta plurala bereizteko erabili ziren, adib. lagunari vs. lagunári; umiari vs. umiári].

- Hitz azentugabeak menpeko aditzaren aurrean

nire diruá emon nau

zure diruá emón nabelá esan dau

zure dirua emón nabelakó esan dau hori

ía zure dirua emón nabén pregunta dau

zure dirua emón nabenián esan dau hori

zure dirua emón naben mutillá ikusi dot.

zure dirua emón nabenétik dabill preguntáten mutilla

ogidxá erosi dau

ogidxá erosí dabelá esan nau

ogidxa erosí dabelakó esan nau hori

ía ogidxa erosí dabén pregunta nau

ogidxa erosí dabenián esan dau hori

ogidxa erosí daben umiá ikusi dot

ogidxa erosí dabenétik dago líbre Jon

beren alabiá ikusi dogu

beren alabiá ikusí dogulá esan dotzagu

beren alabiá ikusí dogulakó pregunta gaitxuz hori

ía beren alabia ikusí dogún pregunta gaitxuz

beren alabia ikusí dogunián abixa dotzagu

beren alabia ikusí daben irakasliák abixa dotzo

beren alabia ikusí dogunétik gagoz hamen

lagunarí deitxu dotzagu

lagunarí deitxú dotzagulá esan dotzat

lagunari deitxú dotzagulakó esan dotzat hori

ía lagunari deitxú dotzagún pregunta nau

lagunari deitxú dotzagunián esan dotzat

lagunari deitxú dotzon neskia dá Míren

lagunari deitxú dotzagunétik dago hasarratúta Míkel

umiarí ekarri dotzo erregalúa

umiarí ekarrí dotzola erregalúa esan dau

umiari ekarrí dotzolako erregalúa ipiñi da pozik

ía umiari ekarrí dotzon erregalúa pregunta dau

umiari ekarrí dotzonian erregalúa ipiñi da pozik 
umiari ekarrí dotzon erregalúa da merkia

umiari ekarrí dotzonétik erregalúa dabill pozik Jone

- Hitz azentudunak menpeko aditzaren aurrean

nire bideúa emon nau

zure bideúa emón nabelá esan dau

zure bideúa emón nabelakó esan dau hori

ía zure bideúa emón nabén pregunta dau

zure bideúa emón nabenián esan dau hori

zure bideúa emón naben mutillá ikusi dot

zure bideúa emón nabenétik dabill preguntáten mutilla

liburúa erosi dau

liburúa erosí dabelá esan nau

liburúa erosí dabelakó esan nau hori

ía liburúa erosí dabén pregunta nau

liburúa erosí dabenián esan dau hori

liburúa erosí daben umiá ikusi dot

liburúa erosí dabenetik dago líbre Jon

beren alábak ikusi doguz

beren alábak ikusí doguzelá esan dotzagu

beren alábak ikusí doguzelakó pregunta gaitxuz hori

ía beren alábak ikusi doguzen pregunta gaitxuz

beren alábak ikusí doguzenián abixa dotzagu

beren alábak ikusí dabezen irakasliák abixa dotzo

beren alábak ikusí doguzenétik gagoz hamen

lagunári deitxu dotzagu

lagunári deitxú dotzagulá esan dotzat

lagunári deitxú dotzagulakó esan dotzat hori

ía lagunári deitxú dotzagún pregunta nau

lagunári deitxú dotzagunián esan dotzat

lagunári deitxú dotzon neskia dá Míren

lagunári deitxú dotzagunétik dago hasarratúta Míkel

umiári ekarri dótze erregalúa

umiári ekarrí dotzéla erregalúa esan dau

umiári ekarrí dotzeláko erregalúa ipiñi da pozik

ía umiári ekarrí dótzen erregalúa pregunta dau

umiári ekarrí dotzenían erregalúa ipiñi da pozik

umiári ekarrí dótzen erregalúa da merkia

umiári ekarrí dotzenétik erregalúa dabill pozik Jóne 
0000 